\title{
Transcervical resection of the endometrium was effective and acceptable at up to 2 years for heavy menstrual bleeding
}

Cooper KG, Parkin DE, Garratt AM, et al. Two-year follow up of women randomised to medical management or transcervical resection of the endometrium for heavy menstrual loss: clinical and quality of life outcomes. Br J Obstet Gynaecol 1999 Mar;106:258-65.

QUESTION: In women with heavy menstrual bleeding, is transcervical resection of the endometrium (TCRE) better than medical management for relieving menstrual symptoms in the long term?

Design

Randomised (concealed*)†, unblinded,* controlled trial with 2-year follow-up.

\section{Setting}

Gynaecology department of a large hospital in Scotland.

\section{Patients}

187 women who consulted a gynaecologist for the first time for heavy menstrual bleeding, were not going to have more children, had a clinical diagnosis of dysfunctional uterine bleeding, had not been referred for surgery, and did not have a treatment preference. Follow-up was 93\% (mean age 42 y).

\section{Intervention}

Women were allocated to TCRE $(n=93)$ or medical management $(\mathrm{n}=94)$. Medical management consisted of progestogens, combined oral contraceptive pill, tranexamic acid, danazol, or hormone replacement therapy and non-steroidal anti-inflammatory drugs.

\section{Main outcome measures}

Gynaecological symptoms, patient satisfaction, acceptability of treatment, and additional treatments were assessed by a mailed questionnaire. The hospital surgical database also provided data on additional treatments. Changes in health-related quality of life were assessed by the Short Form (SF)-36 health survey.

Source of funding:

Scottish Office

Department of Health.

For correspondence:

Dr K G Cooper,

Department of

Obstetrics and

Gynaecology, Aberdeen

Royal Infirmary

Foresterhill, Aberdeen

AB25 2ZB, UK

\section{Main results}

Analysis was by intention to treat. At 2 years, fewer women in the TCRE group than in the medical management group had unchanged or heavier menstrual bleeding $(\mathrm{p}=0.02)$ or required additional treatments $(\mathrm{p}<0.001) \ddagger($ table). 51 of $68(75 \%)$ women in the medicalmanagement group and 15 of $22(68 \%)$ women in the TCRE group who needed additional treatment had surgery. More women in the TCRE group than in the medical management group were satisfied with their

Transcervical resection of the endometrium (TCRE) v medical management for heavy menstrual bleeding

\begin{tabular}{llllll} 
Outcomes at 2 y & TCRE & $\begin{array}{l}\text { Medical } \\
\text { care }\end{array}$ & RRR (95\% Cl) & NNT (CI) \\
\hline Unchanged or increased bleeding & $6 \%$ & $19 \%$ & $69 \%(23$ to 88$)$ & 8 (5 to 31) \\
\hline Needed additional treatment & $25 \%$ & $79 \%$ & $68 \%(54$ to 78$)$ & 2 (2 to 3) \\
\hline & & & $R B I(C l)$ \\
\hline Totally or generally satisfied & $78 \%$ & $56 \%$ & $40 \%(13$ to 76$)$ & 5 (3 to 12) \\
\hline Cure or acceptable improvement & $79 \%$ & $62 \%$ & $29 \%(6$ to 59$)$ & 6 (4 to 25$)$ \\
\hline Treatment acceptable & $91 \%$ & $76 \%$ & $20 \%(5$ to 40$)$ & 7 (4 to 24$)$ \\
\hline
\end{tabular}

§Abbreviations defined in glossary; RRR, RBI, NNT, and $\mathrm{Cl}$ calculated from data in article.

treatment $(\mathrm{p}=0.002)$, were cured or had an acceptable improvement in their symptoms $(\mathrm{p}=0.017)$, and rated their treatment as acceptable $(\mathrm{p}=0.004)$ (table). Women in the TCRE group had improvement in 7 of 8 SF-36 health scores, and women in the medical-management group had improvement in 5 of 8 SF-36 health scores.

\section{Conclusion}

In women with heavy menstrual bleeding, transcervical resection of the endometrium was better than medical management for patient satisfaction and symptom relief.

*See glossary.

† Cooper KG, Parkin DE, Garratt AM, et al. Br J Obstet Gynaecol 1997;104:1360-6.

$\$ p$ value calculated from data in article.

\section{COMMENTARY}

The application of evidence-based gynaecology is necessary, but randomised trials in ambulatory surgery are not easy to do. Cooper and colleagues deserve our congratulations.

2 years after TCRE, 9 of every 10 patients still found this procedure acceptable, and 3 of every 4 women required no additional surgical or medical treatment after their TCRE operation. Thus, having a TCRE reduced the chances of having a hysterectomy the following year, which is the major practice recommendation and point of this paper.

Not so comforting is the disease that the authors were treating in these patients. Heavy menstrual loss is a symptom, not a diagnosis. Dysfunctional uterine bleeding it might be, but the mean haemoglobin concentration was 12.6 g/dl. I will admit to bias of being a "measurer," but I wish the authors had used objective entry criteria for their study. We read more than once that this was a "pragmatic trial," but what is more pragmatic than making a clinical diagnosis?

85 of $272(31 \%)$ eligible patients did not consent to randomisation. Were they more satisfied after 2 years than were the randomised patients?

I believe the authors have shown that early TCRE is an acceptable and effective ambulatory surgical alternative to hysterectomy. However, is it cost-effective? Almost 4 of every 5 women in the medical management group found their treatments acceptable, and medical treatment may still be less expensive and effective enough as the first choice of treatment. A cost-effectiveness study should be the next step in this research.

David Healy, MBBS, PhD Monash University Melbourne, Victoria, Australia 